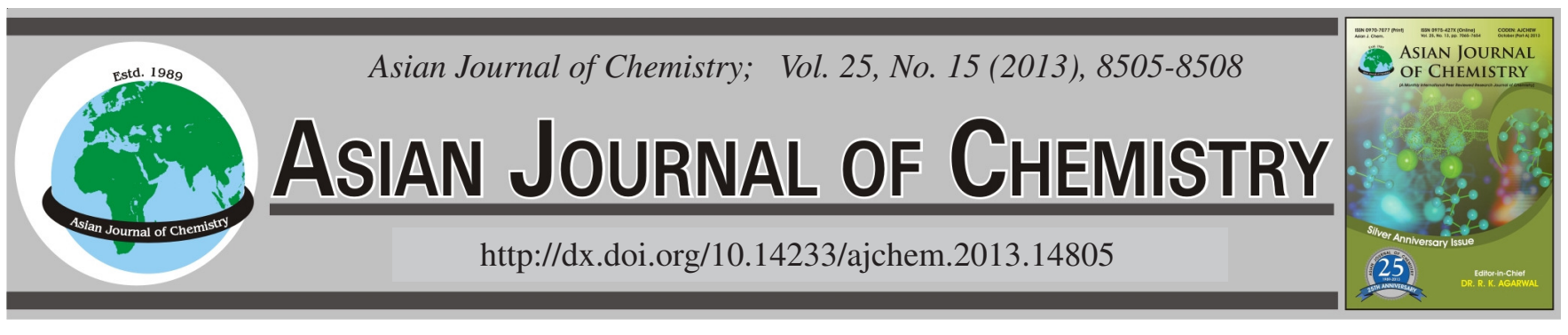

\title{
Synthesis, Characterization and Solvent Effects on the Electronic Absorption Spectra of Aminopyridine Schiff Bases
}

\author{
Cordelia U. Dueke-Eze ${ }^{1}$, Tolulope M. Fasina ${ }^{1, *}$ and Malose J. Mphahlele ${ }^{2}$
}

${ }^{1}$ Department of Chemistry, University of Lagos, Akoka, Lagos State, Nigeria

${ }^{2}$ Department of Chemistry, College of Science, Engineering and Technology, University of South Africa, P.O. Box 392, Pretoria 0003, South Africa

*Corresponding author: Tel: +234 8023063409; E-mail: tfasina@unilag.edu.ng; tofefash@yahoo.ca

\begin{abstract}
Six Schiff bases, namely, N-(2-hydroxylbenzylidene)pyridine-4-amine (IA), N-(2-hydroxylbenzylidene)pyridine-2-amine (IB), N-(5nitro-2-hydroxylbenzylidene)pyridin-4-amine (IIA), N-(5-nitro-2-hydroxylbenzylidene)pyridin-2-amine (IIB), N-(5-bromo-2hydroxylbenzylidene)pyridin-4-amine (IIIA) and N-(5-bromo-2-hydroxylbenzylidene)pyridin-2-amine (IIIB) derived from condensation reactions of 4-aminopyridine or 2-aminopyridine with salicylaldehye, 5-nitrosalicylaldehye and 5-bromosalicylaldehye were synthesized and characterized using elemental analysis, IR, NMR and Raman spectroscopic techniques. The effect of solvent on the electronic absorption spectra was examined in five solvents of different polarities, namely, 1,4-dioxane, chloroform, ethanol, acetonitrile and N,Ndimethyl formamide. The bands involving different electronic transitions were interpreted and regression coefficients calculated for the absorption band involving intermolecular charge transfer transition within the whole Schiff base molecule using an equation that relates the absorption maxima to empirical solvent parameters that depend on the dielectric constant, refractive index and hydrogen bonding ability of the solvents.
\end{abstract}

Key Words: Schiff bases, 2-Aminopyridine, 4-Aminopyridine, Solvent effects, Electronic spectra.

\section{INTRODUCTION}

Compounds containing the pyridine core are important compounds in medicine and pharmaceutical chemistry due to their ability to inhibit enzymes; hence they are currently being used in drugs, vitamins, food flavouring and dyes ${ }^{1,2}$. Pyridinebased Schiff bases, on the other hand, are components of nonlinear optical active (NLO) materials and useful analytical tools ${ }^{3,4}$. An understanding of the electronic structure and spectral properties of compounds provide explanation for the photochemical properties the compounds may exhibit. It is known that the spectral behaviour of any organic compound is strongly related to its structure in both the ground and excited states. Consequently, the spectral behaviour of Schiff bases has been investigated for use in structure elucidation ${ }^{5-7}$. Although the UV-visible spectral behaviour of Schiff bases has been extensively investigated in recent years, the effect of substituent on the electronic absorption peak is considerable less documented in the literature ${ }^{8}$. Very little has been reported on the spectral behaviour of heterocyclic Schiff bases derived from 4-aminopyridine ${ }^{9}$, presumably due to the difficulty in isolation of pure samples of these compounds. We have previously reported the solution state electronic absorption properties of the Schiff bases derived from salicylaldehydes with 2-amino- pyridine ${ }^{10}$. In this paper, we report the effects of solvent and substituents on the electronic absorption spectra of six Schiff bases derived from 4- or 2-aminopyridine with 5-substituted salicylaldehyde derivatives. In an attempt to evaluate the solvent-solute interactions effect on the absorption spectra, the correlation data was computed by regression analysis on the intramolecular charge transfer absorption peak.

\section{EXPERIMENTAL}

All chemicals were obtained commercially from Aldrich Chemicals. Solvents: 1,4-dioxane, chloroform, ethanol, acetonitrile, toluene and N,N-dimethyl formamide (DMF) were of spectroscopic or analytical grade and used without further purification. Melting points were determined on a Stuart SMP3 melting point apparatus and are uncorrected. Elemental analyses were performed with a Perkin -Elmer $2400 \mathrm{CHNS} / \mathrm{O}$ analyzer. Electronic spectra were recorded for solutions of the Schiff bases on a Cecil Super Aquarius 9000 series UV-visible spectrophotometer using $1 \mathrm{~cm}$ quartz cell at room temperature immediately after preparing the solutions. The IR spectra were recorded on an FTS 7000 series Digilab Win-IR Pro spectrometer equipped with a diamond ATR (attenuated total reflectance) accessory by using the thin-film method. The Raman 
spectroscopic analysis was carried out using MultiRam FRRaman Spectrometer with Nd-YAG laser which lases in the near infrared at $1064 \mathrm{~nm}$ equipped for the collection of fluorescence-free Raman spectra. ${ }^{1} \mathrm{H}$ and ${ }^{13} \mathrm{C}$ NMR were recorded on a Varian Mercury $300 \mathrm{MHz}$ NMR spectrometer and the chemical shifts are quoted relative to the solvent peaks.

\section{Preparation of 4-amino-pyridine Schiff bases (IA-IIIA)}

N-(2-Hydroxylbenzylidene)pyridin-4-amine (IA): A degassed mixture of 4-aminopyridine (75 mg, $8.0 \mathrm{mmol}$ ), 2-hydroxybenzaldehyde (98 $\mathrm{mg}, 8.0 \mathrm{mmol}$.) and $p$-toluene sulfonic acid monohydrate $(10 \mathrm{mg})$ in dry toluene $(100 \mathrm{~mL})$ under nitrogen atmosphere was refluxed under Dean-Stark conditions for $24 \mathrm{~h}$. The solvent was removed under reduced pressure and the residue recrystallized to afford IA as a deep yellow solid (12.80 mg, $81 \%$ ); m.p. $76.5{ }^{\circ} \mathrm{C}$ (toluene). IR (ATR, $v_{\max }, \mathrm{cm}^{-1}$ ) 1618, 1600, 1595, 1454, 1247, 1172, 1140, 840, 738; Raman (solid/1064 nm): 3059, 1618, 1585, 1502, $1487,1453,1403,1364,1334,1284,1188,993,778,663 ;{ }^{1} \mathrm{H}$ NMR (300 MHz, $\left.\mathrm{CDCl}_{3}\right) \delta_{\mathrm{H}}: 6.95-7.05(\mathrm{~m}, 2 \mathrm{H}), 7.14(\mathrm{~d}, J=$ $6.6 \mathrm{~Hz}, 2 \mathrm{H}), 7.46(\mathrm{t}, J=15.6 \mathrm{~Hz}, 2 \mathrm{H}), 8.61(\mathrm{~s}, 1 \mathrm{H}), 8.65(\mathrm{~d}$, $J=5.4 \mathrm{~Hz}, 2 \mathrm{H}), 12.57(\mathrm{~s}, 1 \mathrm{H}) .{ }^{13} \mathrm{C} \mathrm{NMR}\left(75 \mathrm{MHz}, \mathrm{CDCl}_{3}\right)$ $\delta_{\mathrm{C}}: 116.10,151.15,155.46,117.50,118.64,119.45,132.92$, 134.37, 161.29, 165.68. Anal. calcd. (\%) for $\mathrm{C}_{12} \mathrm{H}_{10} \mathrm{~N}_{2} \mathrm{O}: \mathrm{C}$, 72.71, H, 5.08, N, 14.13. Found (\%): C, 72.62, H, 5.02, N, 13.96.

N-(5-Nitro-2-hydroxylbenzylidene)pyridin-4-amine (IIA): Yellow solid (14.60 mg, 75 \%); m.p. 193.7-194.1 ${ }^{\circ} \mathrm{C}$ (toluene). IR (ATR, $v_{\max }, \mathrm{cm}^{-1}$ ): 1620, 1610, 1572, 1540, 1460, 1440, 1396, 1326, 1178, 1100, 960, 930, 863, 827, 770, 720, 660; Raman (solid/1064 nm): 1610, 1590, 1561, 1461, 1341, 1213, 1096, 995, 626; ${ }^{1} \mathrm{H}$ NMR $\left(300 \mathrm{MHz}, \mathrm{CDCl}_{3}\right) \delta_{\mathrm{H}}$ : 7.09$7.22(\mathrm{~m}, 3 \mathrm{H}), 8.30-8.44(\mathrm{~m}, 2 \mathrm{H}), 8.56(\mathrm{~s}, 1 \mathrm{H}), 8.717(\mathrm{t}, J=$ $8.4 \mathrm{~Hz}, 2 \mathrm{H}), 10.01 ;{ }^{13} \mathrm{C}$ NMR $\delta: 115.94,118.58,119.04,128.95$, 129.30, 129.67, 131.63, 151.44, 164.14, 166.39. Anal. calcd. (\%) for $\mathrm{C}_{12} \mathrm{H}_{9} \mathrm{~N}_{3} \mathrm{O}_{3}: \mathrm{C}, 59.26, \mathrm{H}, 3.70, \mathrm{~N}, 17.28$. Found (\%): C, 58.96, H, 3.67, N, 17.06.

N-(5-Bromo-2-hydroxylbenzylidene)pyridin-4-amine (IIIA): Orange crystals (18.60 mg, $84 \%$ ); m.p. 139.5-140.2 ${ }^{\circ} \mathrm{C}$ (toluene). IR (ATR, $v_{\max }, \mathrm{cm}^{-1}$ ): 1614, 1560, 1543, 1471, 1410, 1353, 1272, 1180, 1077, 915, 864, 626; Raman (solid/ $1064 \mathrm{~nm}$ ): 3057, 1587, 1566, 1478, 1437, 1382, 1280, 1187, 994, 784, 665; ${ }^{1} \mathrm{H}$ NMR $\left(300 \mathrm{MHz}, \mathrm{CDCl}_{3}\right) \delta_{\mathrm{H}}: 6.96(\mathrm{~d}, J=$ $8.7 \mathrm{~Hz}, 2 \mathrm{H}), 7.13(\mathrm{~d}, J=5.4 \mathrm{~Hz}, 2 \mathrm{H}), 7.48-7.54(\mathrm{~m}, 2 \mathrm{H}), 8.54$ $(\mathrm{s}, 1 \mathrm{H}), 8.66(\mathrm{~s}, 2 \mathrm{H}), 12.57(\mathrm{~s}, 1 \mathrm{H}) ;{ }^{13} \mathrm{C} \mathrm{NMR}\left(75 \mathrm{MHz}, \mathrm{CDCl}_{3}\right)$ $\delta_{\mathrm{C}}: 110.88,116.05,119.53,119.97,134.80,136.93,151.26$, 154.93, 160.27, 164.382. Anal. calcd. (\%) for $\mathrm{C}_{12} \mathrm{H}_{9} \mathrm{~N}_{2} \mathrm{OBr}$ : C, 52.01, H, 3.27, N, 10.11. Found (\%): C, 52.16, H, 3.18, N, 9.82 .

\section{Preparation of 2-amino- pyridine Schiff bases (IB-IIIB)}

N-(2-Hydroxylbenzylidene)pyridine-2-amine (IB): A solution of 2-hydroxybenzaldehyde ( $24.5 \mathrm{mg}, 0.20 \mathrm{mmol})$ in ethanol $(10 \mathrm{~mL})$ and two drops of formic acid were added to a stirred solution of 2-aminopyridine $(18.8 \mathrm{mg}, 0.20 \mathrm{mmol})$ in ethanol $(10 \mathrm{~mL})$. The reaction mixture was refluxed for $6 \mathrm{~h}$ and then allowed to cool to room temperature. The resulting precipitate was filtered and recrystallized to afford IB as a yellow-orange solid (0.14 mg, $35 \%)$; m.p. $63-64^{\circ} \mathrm{C}$ (1:1, ethanol- hexane). IR (ATR, $v_{\max }, \mathrm{cm}^{-1}$ ): 3434, 2925, 1613, 1589, 1463, 1377, 1278, 1256, 1148, 993, 915, 845, 790, 732,578; Raman (solid/1064 nm): 3059, 1618, 1586, 1567, 1487, 1285, 1226, 1188, 1032, 994, 778, 664; ${ }^{1} \mathrm{H}$ NMR $\left(300 \mathrm{MHz}, \mathrm{CDCl}_{3}\right) \delta_{\mathrm{H}}$ : 6.91-8.49 (m, 8H), $9.41(\mathrm{~s}, 1 \mathrm{H}), 13.40(\mathrm{~s}, 1 \mathrm{H}) ;{ }^{13} \mathrm{C}$ NMR $(75$ $\left.\mathrm{MHz}, \mathrm{CDCl}_{3}\right) \delta_{\mathrm{C}}: 117.21,118.93,119.19,120.44,122.54$, 133.44, 133.81, 138.45, 148.92, 151.51, 161.82, 164.70. Anal. calcd. (\%) for $\mathrm{C}_{12} \mathrm{H}_{10} \mathrm{~N}_{2} \mathrm{O}$ : C, 72.72, H, 5.05, N, 14.14. Found (\%) C, 72.33, H, 5.03, N, 14.00.

N-(5-Nitro-2-hydroxylbenzylidene)pyridin-2-amine (IIB): Yellow solid (0.22 mg, $46 \%)$; m.p. 182-184 ${ }^{\circ} \mathrm{C}(1: 1$, ethanol-hexane). IR (ATR, $\left.v_{\max }, \mathrm{cm}^{-1}\right): 3053,1615,1585,1527$, 1463, 1430, 1332, 1289, 1108, 1090, 992, 895, 829, 787, 706, 639; Raman (solid): 3051, 1631, 1579, 1557, 1463, 1332, 1215 , 994, 792, 625; ${ }^{1} \mathrm{H}$ NMR (300 MHz, $\left.\mathrm{CDCl}_{3}\right) \delta_{\mathrm{H}}: 7.10-8.54(\mathrm{~m}$, $7 \mathrm{H}), 9.53$ (s, 1H), 14.56 (s, 1H); ${ }^{13} \mathrm{C} \mathrm{NMR}\left(75 \mathrm{MHz}, \mathrm{CDCl}_{3}\right)$ $\delta_{\mathrm{C}}: 117.79,118.49,120.51,123.60,128.90,129.52,131.63$, 138.76, 149.25, 155.78, 162.89, 167.63. Anal. calcd. (\%) for $\mathrm{C}_{12} \mathrm{H}_{9} \mathrm{~N}_{3} \mathrm{O}_{3}: \mathrm{C}, 59.26, \mathrm{H}, 3.70, \mathrm{~N}, 17.28$. Found (\%): C, 59.14, H, 3.56, N, 16.96.

N-(5-Bromo-2-hydroxylbenzylidene)pyridin-2-amine (IIIB): Light-orange crystal $(0.45 \mathrm{mg}, 80.94 \%)$; m.p. 138$140^{\circ} \mathrm{C}\left(1: 1\right.$, ethanol-hexane). IR (ATR, $\left.v_{\max }, \mathrm{cm}^{-1}\right)$ : 2640, 1607 , 1582, 1461, 1431, 1381, 1341, 1271, 1179, 1073, 991, 915, 871, 812, 783, 739, 699, 624; Raman (solid/1064 nm): 3055, 1609, 1589, 1550, 1446, 1310, 1276, 1226, 1184, 994, 785, 625; ${ }^{1} \mathrm{H}$ NMR $\left(300 \mathrm{MHz}, \mathrm{CDCl}_{3}\right) \delta_{\mathrm{H}}: 6.89-8.49(\mathrm{~m}, 7 \mathrm{H}), 9.34$ $(\mathrm{s}, 1 \mathrm{H}), 13.42(\mathrm{~s}, 1 \mathrm{H}) ;{ }^{13} \mathrm{C} \mathrm{NMR}\left(75 \mathrm{MHz}, \mathrm{CDCl}_{3}\right) \delta_{\mathrm{C}}: 110.60$, 119.28, 120.35, 120.65, 122.99, 135.26, 136.36, 138.56, 149.05, 156.98, 163.40. Anal. calcd. (\%) for $\mathrm{C}_{12} \mathrm{H}_{9} \mathrm{~N}_{2} \mathrm{OBr}$ : C, 51.98, H, 3.24, N, 10.10. Found (\%): C, 51.96, H, 3.21, N, 9.88 .

\section{RESULTS AND DISCUSSION}

Synthesis: Condensation of 4-aminopyridine with substituted 2-hydroxybenzaldehydes, in dry toluene under DeanStark conditions in the presence of $p$-toluene sulfonic acid as catalyst afforded the corresponding air stable Schiff bases IAIIIA in good yields and high purity resulting in sharp melting point values (Scheme-I). Attempted reactions in absence of the catalyst or using ethanol as solvent led to complicated mixture of products that were difficult to isolate by column chromatography. Elemental analyses data also fit well the composition suggested for the compounds (Table-1). Characteristic IR and ${ }^{1} \mathrm{H}$ NMR peaks for the Schiff bases are listed in Table-2. The IR spectra of the compounds show no presence of the carbonyl stretch for the aldehydic group, but reveal the presence of an intense band in the region $\mathrm{v} 1614-1607 \mathrm{~cm}^{-1}$ due to imine group $(\mathrm{C}=\mathrm{N})$ stretching vibration. The IR absorption bands at $v \mathrm{ca} .1247-1326 \mathrm{~cm}^{-1}$ in the spectra of these compounds are due to the $\mathrm{C}-\mathrm{O}$ stretching vibration of the phenolic group. Despite the $\mathrm{C}-\mathrm{O}$ stretching vibration, only the IR spectrum of the 2-aminopyridine derivatives revealed the presence of the $v(\mathrm{OH})$ stretching vibration at $3438-3434 \mathrm{~cm}^{-1}$ typical of the phenolic -OH. The absence of the $\mathrm{O}-\mathrm{H}$ band in the IR spectra of the Schiff bases derived from 4-aminopyridine compounds is probably the result of resonance stabilization with the keto form of the compound. The ${ }^{1} \mathrm{H}$ NMR spectra of 
TABLE-1

ANALYTICAL DATA (CHN ANALYSIS) OF THE SCHIFF BASES IA-IIIB

\begin{tabular}{ccccccc}
\hline Compound & Empirical formula & m.p. $\left({ }^{\circ} \mathrm{C}\right)$ & Yield $(\%)$ & $\mathrm{C}(\%)$ (calcd.) found & $\mathrm{H}(\%)$ (calcd.) found & $\mathrm{N}(\%)$ (calcd.) found \\
\hline IA & $\mathrm{C}_{12} \mathrm{H}_{10} \mathrm{~N}_{2} \mathrm{O}$ & 76.5 & 81 & $(72.71) 72.62$ & $(5.08) 5.02$ & $(14.13) 13.96$ \\
IB & $\mathrm{C}_{12} \mathrm{H}_{10} \mathrm{~N}_{2} \mathrm{O}$ & 63 & 35 & $(72.71) 72.33$ & $(5.08) 5.03$ & $(14.14) 14.00$ \\
IIA & $\mathrm{C}_{12} \mathrm{H}_{9} \mathrm{~N}_{3} \mathrm{O}_{3}$ & 194 & 75 & $(59.26) 58.96$ & $(3.73) 3.67$ & $(17.28) 17.06$ \\
IIB & $\mathrm{C}_{12} \mathrm{H}_{9} \mathrm{~N}_{3} \mathrm{O}_{3}$ & 184 & 46 & $(59.26) 59.14$ & $(3.73) 3.56$ & $(17.28) 16.96$ \\
IIIA & $\mathrm{C}_{12} \mathrm{H}_{9} \mathrm{~N}_{2} \mathrm{OBr}$ & 140 & 84 & $(52.01) 52.16$ & $(3.27) 3.18$ & $(10.11) 9.82$ \\
IIIB & $\mathrm{C}_{12} \mathrm{H}_{9} \mathrm{~N}_{2} \mathrm{OBr}$ & 139 & 81 & $(52.01) 51.96$ & $(3.27) 3.21$ & $(10.10) 9.88$ \\
\hline
\end{tabular}

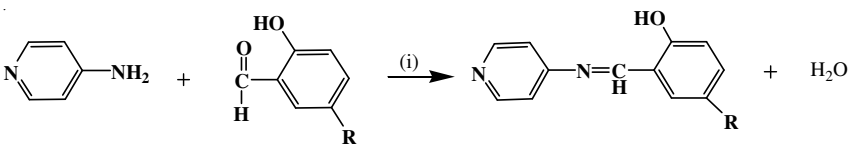

(IA) $\mathrm{R}=\mathrm{H}(81 \%)$, (IIA) $\mathrm{R}=\mathrm{NO}_{2}(75 \%)$, (IIIA) $\mathrm{R}=\mathrm{Br}(84 \%)$. Reagents and conditions: (i) $p$-toluenesulphonic acid (cat.), toluene, $\mathrm{N}_{2}(\mathrm{~g})$, heat, $24 \mathrm{~h}$

Scheme-I: Synthesis of the Schiff bases from 4-aminopyridine and salicylaldehyde derivatives

\begin{tabular}{ccccc}
\multicolumn{5}{c}{ TABLE-2 } \\
\multicolumn{5}{c}{$\begin{array}{c}\text { CHARACTERISTIC IR AND }{ }^{1} \text { HNMR PEAKS } \\
\text { FOR THE SCHIFF BASES IA-IIIB }\end{array}$} \\
\hline \multirow{2}{*}{ Compound } & $\begin{array}{c}v(\mathrm{C}=\mathrm{N}) \\
\mathrm{cm}^{-1}\end{array}$ & $\begin{array}{c}v(\mathrm{O}-\mathrm{H}) \\
\mathrm{cm}^{-1}\end{array}$ & $\begin{array}{c}v(\mathrm{C}-\mathrm{O}) \\
\mathrm{cm}^{-1}\end{array}$ & $\begin{array}{c}\delta_{\mathrm{H}}(\mathrm{CH}=\mathrm{N}) \\
\mathrm{ppm}\end{array}$ \\
\hline IA & 1618 & - & 1247 & 8.61 \\
IB & 1613 & 3434 & 1278 & 9.41 \\
IIA & 1620 & - & 1326 & 8.56 \\
IIB & 1615 & 3438 & 1289 & 9.53 \\
IIIA & 1614 & - & 1272 & 8.54 \\
IIIB & 1607 & - & 1271 & 9.34 \\
\hline
\end{tabular}

these compounds reveal the presence of a sharp singlet at $\delta$ 8.61-8.54 ppm for the 2-aminopyridine Schiff bases and $\delta$ 9.34$9.53 \mathrm{ppm}$ for the 4-aminopyridine derivatives, which further confirm their imine nature.

Electronic spectra: The electronic absorption spectra of the compounds were acquired in five solvents of different polarities, namely, 1,4-dioxane, chloroform, ethanol, acetonitrile and dimethyl formamide (DMF) in order to study the effects of solvent on the spectral properties of the compounds (Table$3)$. The spectra of the compounds are affected both by the nature of substituent (Fig. 1) and solvent used (Fig. 2). While the high/medium energy bands appear insensitive to substitution pattern, the absorption maxima of the intramolcular charge transfer bands vary with nature of substituent in a given solvent.

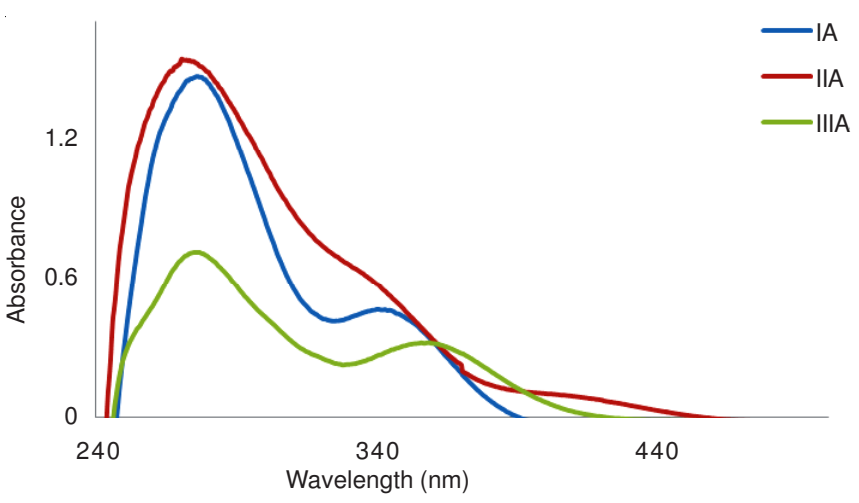

Fig. 1. Electronic spectra of compounds IA-IIIA in chloroform

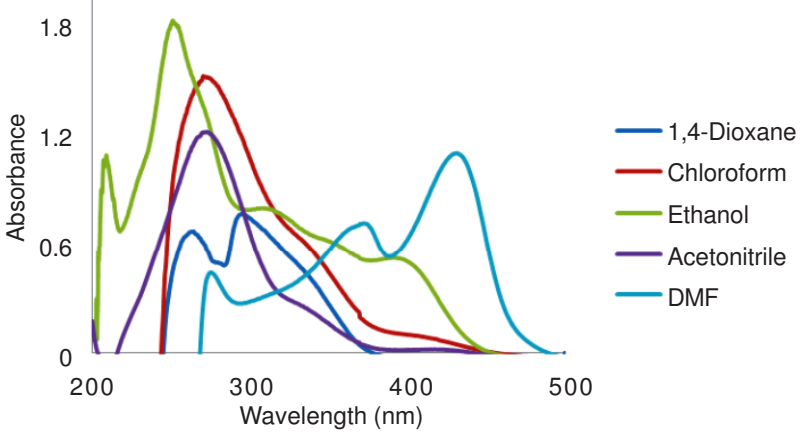

Fig. 2. Electronic spectra of IIA in different solvents

The spectra of these compounds in the five solvents comprise of several absorption bands in the region $\mu$ 200-500 nm (Fig. 2, Table-3). The bands located in the wavelength range 209-280 nm (bands A and B) in the spectra of all Schiff bases can be assigned to excitation of the $\pi$ electrons of the aromatic system ${ }^{11}$. The third band observed in the wavelength range $280-310 \mathrm{~nm}$ is assigned to transition between the $\pi$ orbital localized on the central bond of the azomethine group. The fourth band located in the range $330-400 \mathrm{~nm}$ (Band D) is due to intermolecular charge transfer transition within the whole Schiff base molecule it is based on strong intermolecular hydrogen bonding between the hydroxyl group on the salicylidene part of the molecule and the azomethine nitrogen ${ }^{12}$. These charge transfer bands are more sensitive to solvent changes than bands arising from local transitions.

\begin{tabular}{|c|c|c|c|c|c|c|}
\hline \multicolumn{7}{|c|}{$\begin{array}{c}\text { TABLE-3 } \\
\lambda_{\max }(\mathrm{nm}) \text { VALUES FOR THE SCHIFF BASES } \\
\text { IA-IIIB IN DIFFERENT SOLVENTS }\end{array}$} \\
\hline Solvent & IA & IB & IIA & IIB & IIIA & IIIB \\
\hline \multirow{3}{*}{$\begin{array}{c}1,4- \\
\text { Dioxane }\end{array}$} & 267 & 269 & 264 & 297 & 270 & 306 \\
\hline & 292 & 305 & 296 & - & 296 & 360 \\
\hline & 339 & 351 & 360 & - & 358 & - \\
\hline \multirow{3}{*}{ Chloroform } & 276 & 270 & 273 & 266 & 277 & 275 \\
\hline & 343 & 307 & - & 303 & 358 & 308 \\
\hline & - & 352 & - & 334 & - & 360 \\
\hline \multirow{4}{*}{ Ethanol } & 221 & 207 & 209 & 233 & 208 & 255 \\
\hline & 272 & 268 & 251 & 300 & 234(sh) & 298 \\
\hline & 340 & 305 & 308 & 348 & 251 & 354 \\
\hline & - & 347 & 391 & 387 & 354 & - \\
\hline \multirow{5}{*}{ Acetonitrile } & 227 & 222 & 273 & 222 & 232 & 277(sh) \\
\hline & 274 & 267 & 339 & 259 & 272 & 268 \\
\hline & 337 & 305 & 418 & 303 & 348 & 307 \\
\hline & - & 346 & - & 336 & - & 355 \\
\hline & - & - & - & 437 & - & - \\
\hline \multirow{3}{*}{ DMF } & 279 & 268 & 276 & 209 & 279 & 255 \\
\hline & 336 & 300 & 372 & 377 & 351 & 302 \\
\hline & - & - & 432 & 429 & - & 361 \\
\hline
\end{tabular}


A fifth band observed above $400 \mathrm{~nm}$ can be ascribed to the intermolecular CT from solvent to the antibonding orbital of the $\mathrm{OH}$ bond of the salicyladehyde moiety. This charge transfer transition in the aprotic polar solvents, DMF and acetonitrile is assumed to take place through interaction between the solute and solvent molecules via hydrogen bonding resulting in formation of a solute-solvent molecule complex with the proton acting as bridge between the two molecules ${ }^{11}$. This effect is particularly observed in the spectra of IIA and IIB containing the strongly electron withdrawing nitro substituent (Fig. 2).

Effect of solvents: The influence of solvent on intermolecular charge transfer transition within the whole Schiff base molecule (band D) in the investigated compounds was studied using an empirical expression for evaluation of solvent effects $^{13}$ :

$$
\mathrm{Y}=\mathrm{a}_{0}+\mathrm{a}_{1} \mathrm{X}_{1}++\mathrm{a}_{2} \mathrm{X}_{2}+\mathrm{a}_{3} \mathrm{X}_{3}+\ldots+\mathrm{a}_{\mathrm{n}} \mathrm{X}_{\mathrm{n}}
$$

The observed peak location (Y) is considered as the dependent variable while the independent variables are the solvent interaction mechanism E, K, M, N (Table-4).

\begin{tabular}{|c|c|c|c|c|c|c|}
\hline \multicolumn{7}{|c|}{$\begin{array}{c}\text { TABLE-4 } \\
\text { SOLVENT DIELECTRIC CONSTANT, REFRACTIVE } \\
\text { INDEX AND OTHER POLARITY PARAMETERS } \\
\text { USED IN SPECTRAL CORRELATION }\end{array}$} \\
\hline Solvent & $\mathrm{D}$ & $\eta$ & $\mathrm{E}$ & $\mathrm{K}$ & M & $\mathrm{N}$ \\
\hline Dioxane & 2.2 & 1.422 & 36.0 & 0.22 & 0.20 & 0.03 \\
\hline Dimethyl formamide & 36.7 & 1.427 & 43.8 & 0.48 & 0.20 & 0.67 \\
\hline Acetonitrile & 37.5 & 1.344 & 45.0 & 0.48 & 0.18 & 0.71 \\
\hline Chloroform & 4.7 & 1.443 & 39.1 & 0.36 & 0.21 & 0.03 \\
\hline Ethanol & 24.3 & 1.361 & 51.9 & 0.47 & 0.18 & 0.67 \\
\hline
\end{tabular}

The parameter $\mathrm{E}$ is an empirical solvent polarity parameter sensitive to both solvent-solute hydrogen bonding and dipolar interactions. $\mathrm{K}$ depends on the solvent dielectric constant $\mathrm{D}$ and is a measure of the polarity of the solvent. $\mathrm{M}$ depends on the solvent refractive index $\eta$ and it measures solute permanent dipole-solvent induced dipole interactions while $\mathrm{N}$ is a measure of permanent dipole-permanent dipole interactions and it is dependent on both refractive index and dielectric constant.

A multiple regression analysis has been performed and in each case fits are obtained as a function of one, two or three parameters. The results are listed in Table-5

The influence of empirical solvent polarity on the position of absorption band is evident by the high correlation coefficients (greater than 0.5) computed for salicylidimines with the $\mathrm{E}$ parameter in IB, IIA, IIB, IIIB. The high correlation values obtained using the parameter $\mathrm{K}$ indicates high influence of the dielectric constant on position of the absorption peak in IB, IIA, IIB, IIIB. The solute permanent dipole-solvent induced dipole interactions (parameter $\mathrm{M}$ ) play a major role in the spectra of Schiff bases. IA, IB, IIB and the permanent dipole-permanent dipole interactions (parameter $\mathrm{N}$ ) has important effect IB, IIA, IIB, IIIB. While IIIA has low correlation coefficients with any individual solvent factor, it is dependent on all measures of solvent polarity used. The use of three-parameters equations shows an improvement in fits over two parameters and one parameter equations.
TABLE-5

REGRESSION ANALYSIS VALUES OF MULTIPLE

CORRELATION COEFFICIENTS FOR SOLVENT PARAMETERS

\begin{tabular}{ccccccc}
\hline Parameters & IA & IB & IIA & IIB & IIIA & IIIB \\
\hline E & 0.223 & 0.835 & 0.588 & 0.678 & 0.445 & 0.800 \\
K & 0.380 & 0.806 & 0.790 & 0.595 & 0.168 & 0.509 \\
M & 0.702 & 0.679 & 0.471 & 0.522 & 0.119 & 0.475 \\
N & 0.485 & 0.889 & 0.855 & 0.517 & 0.115 & 0.553 \\
EK & 0.426 & 0.844 & 0.807 & 0.688 & 0.603 & 0.865 \\
EM & 0.705 & 0.919 & 0.644 & 0.685 & 0.499 & 0.819 \\
EN & 0.625 & 0.889 & 0.906 & 0.678 & 0.660 & 0.846 \\
KM & 0.795 & 0.990 & 0.871 & 0.652 & 0.226 & 0.653 \\
KN & 0.844 & 0.998 & 0.938 & 0.989 & 0.207 & 0.614 \\
MN & 0.767 & 0.995 & 0.891 & 0.522 & 0.935 & 0.648 \\
EKM & 0.989 & 1.0 & 0.961 & 1.0 & 1.0 & 0.867 \\
EKN & 0.943 & 1.0 & 0.991 & 1.0 & 1.0 & 0.879 \\
KMN & 0.861 & 1.0 & 0.998 & 1.0 & 1.0 & 0.667 \\
EMN & 0.982 & 1.0 & 0.977 & 1.0 & 1.0 & 0.858 \\
\hline
\end{tabular}

\section{Conclusion}

Solvent and substituent effects on the electronic absorption spectra of 2-amino and 4-aminopyridine Schiff bases have been investigated using five different organic solvents. Intramolecular charge transfer band of the prepared compounds studied revealed that the multi-parameter eqn. 1 gave high multiple correlation coefficient values. This indicates that the applied empirical expression is successful in evaluation of solvent effects on electronic absorption spectra of the studied Schiff bases. Further work to understand the solvent dependence on the tautomeric inverconversion and biological activity for this group of Schiff bases is currently underway.

\section{ACKNOWLEDGEMENTS}

The authors are grateful to the Department of Chemistry (University of South Africa) and the NRF (South Africa) for financial support.

\section{REFERENCES}

1. V.I. Savchenko, V.G. Dorokhov, I.K. Yakushchenko, I.N. Zyuzin and S.M. Aldoshin, Herald Russ. Acad. Sci., 80, 149 (2010).

2. M.C.S. Lourenco, M.V.N. de Souza, A.C. Pinheiro, M.L. Ferreira, R.S.B. Goncalves, T.C.M. Nogueira and M.A. Peralta, Arkivoc, 181 (2007).

3. M. Sliwa, S. Letard, I. Malfat, M. Nierlich, P.G. Lacroix, T. Asahi, H. Masuhara, P. Yu and K. Nakatani, Chem. Mater., 17, 4727 (2005).

4. M. Rodriguez, G. Ramos-Ortiz, J.L. Maldonado, V.M. Herrera-Ambriz, O. Dominguez, R. Santillan, N. Farfan and K. Nakatani, Spectrochim. Acta A, 79, 1757 (2011).

5. D. Guha, A. Mandal, A. Koll, A. Filarowski and S. Mukherjee, Spectrochim. Acta A, 56, 2669 (2000).

6. R.M. Issa, S.A. El-Dali and N.A. El-Wakiel, Spectrochim. Acta A, 59, 723 (2003).

7. E. Hadjoudis and I.M. Mavridis, Chem. Soc. Rev., 33, 579 (2004).

8. N. Galic, Z. Cimerman and V. Tomisic, Spectrochim. Acta A, 71, 1274 (2008).

9. M.H. Al-Douh, A.A. Al-Fatlawy and O.H. Abid, Had. Studies Res., 4, 1 (2003).

10. C.U. Dueke-Eze and T.M. Fasina, Int. J. Chem. Sci., 4, 9 (2011).

11. M.A. El-Gahami, Z.A. Khfagi and S.A. Ibrahim, Can. J. Appl. Spectrosc., 36, 108 (1991).

12. S.P. Sovilj, V.M. Vasiae, D.L. Stojiae, B. Stojeeva-Radovanovi and L.T. Petkovska, Spectrosc. Lett., 31, 1107 (1998).

13. H.H. Hammud, A. Ghannoum and M.S. Masoud, Spectrochim. Acta A, 63, 255 (2006) 